\title{
ENTRE O CANDOMBLÉ E A CULTURA: Edison Carneiro e os estudos culturais afro-brasileiros
}

\author{
BETWEEN CANDOMBLÉ AND CULTURE: Edison Carneiro and \\ Afro-Brazilian cultural studies
}

Anderson Santos Cordeiro*

\section{Resumo}

Este artigo busca mostrar a importância da obra de Edison Carneiro, intelectual baiano e negro, que ao longo de sua vida debruçou-se sobre os estudos culturais e afro-brasileiros, principalmente no tocante às religiões de matrizes africanas. Para isso, se propõe a descrever sua biografia, e mostrar os percalços que o intelectual sofreu e ainda sofre por falta do (re)conhecimento. O trabalho pretende mostrar a relevância dos estudos que desempenhou ao longo de sua vida, e apresentar as contribuições e críticas que seus trabalhos desempenharam no campo da sociologia e antropologia.

Palavras-chaves: Candomblé; Cultura; Negritude; Edison Carneiro.

\begin{abstract}
The article seeks to show the importance of the work of Edison Carneiro, a Bahian and black intelectual, who throughout his life has focused on cultural and Afro-Brazilian studies, especially with regard to African-based religions. For this, the article proposes to describe, roughly speaking, his biography, and to show the obstacles that the intellectual suffered and still suffers for lack of (re)knowledge. The article aims to demonstrate the relevance of the research carried out throughout his life, and to examine the contribution and criticism of his works in the field of sociology and anthropology.
\end{abstract}

Keywords: Candomblé; Culture; Blackness; Edison Carneiro.

*Aluno do Curso de Ciências Sociais da UFPB/Brasil. E-mail: andersondsc97@gmail.com. 


\section{Introdução}

Ouves? É o chamado insistente dos atabaques na noite misteriosa. Se vieres eles tocarão mais alto ainda, no poderoso toque do "chamado do santo" $e$ os deuses negros chegarão das florestas d'África para dançar em tua honra.

JORGE AMADO (1973)

Pensar em cultura e seus moldes não é uma tarefa fácil, e quando se fala de cultura afro-brasileira, cultura africana e intelectuais negro(a)s, estamos lidando com um campo vasto e ao mesmo tempo ainda desconhecido. Na epígrafe de Jorge Amado, que consta em seu livro Bahia de todos os santos (AMADO, 1973), o misticismo e o "chamado do santo" podem ser interpretados como os motivos que fizeram Edison Carneiro ter tanto fascínio pelo estudo do candomblé e pelas variantes das religiões afro. Carneiro, nesse enredo, revela não só o apreço pelas religiões como também pela cultura negra e popular como pilar para se entender a cultura brasileira. Teve a sua inserção no campo das relações raciais e da religião a partir da década de 1930, cuja trajetória o conduziu para as ciências sociais, principalmente a antropologia e a sociologia.

Da própria Bahia, nascido em Salvador, em agosto de 1912, Edison Carneiro teve uma inserção precoce dentro da elite pensante baiana, pois sua família tinha contatos com esses grupos. Advindo de um estrato social de condição econômica instável, transitando entre a estabilidade e a penúria, mesmo com o prestígio intelectual que seu pai desfrutava, a instabilidade política da Primeira República não os deixou de fora de eventuais agruras que atingiam diretamente famílias que não eram da elite econômica, como os Souza Carneiro (ROSSI, 2015). A família desfrutou dessas boas relações, fazendo com que o jovem intelectual vivenciasse os novos ares que a média e alta sociedades baianas podiam lhe oferecer. Teve contato na Academia dos Rebeldes ${ }^{1}$, da qual participou com ilustres pensadores que posteriormente ficariam gravados na cena intelectual nacional, como

\footnotetext{
${ }^{1}$ A academia dos Rebeldes foi fundada por Jorge Amado, antecipava a ênfase social do Romance na década de 30 e do teor realista da literatura pregando uma arte moderna sem ser modernista. Para mais informações ver Soares, 2006.
} 
Jorge Amado, Aydano do Couto Ferraz, Pinheiro Viegas, entre outros jovens aspirantes a intelectuais das décadas de 1920/30 em Salvador (BIAGGIO; COUCEIRO, 2009).

Neste trabalho, procuraremos apresentar as principais obras do autor que o ajudaram a se consolidar no campo da cultura e das religiões afro, além dos impasses que causaram num momento singular da consolidação e institucionalização das ciências sociais no Brasil. Nessa perspectiva, o trabalho de Carneiro nos ajuda a compreender os paradigmas que rodeiam a imagem do negro e das religiões de matrizes africanas, colaborando para estudiosos que posteriormente seguiram na mesma trajetória de observação e análise sobre o candomblé, folclore e a cultura popular brasileira.

Para uma melhor compreensão da trajetória do autor, mesmo não sendo um trabalho que busque fazer uma biografia completa como fez Gustavo Rossi ${ }^{2}$, este trabalho será dividido em três partes: a primeira buscando compreender sua trajetória enquanto intelectual em formação, e a carreira que obteve enquanto pesquisador multifacetado, sendo intitulada $A$ história do ogã intelectual. A segunda parte volta-se para as suas principais obras e seus trabalhos, dando ênfase às contribuições para o estudo das relações raciais e culturais e possíveis críticas; buscando entender aspectos que ainda hoje são influência na forma de se pesquisar as religiões afro-brasileiras, intitulada $D a$ "quase" branquitude aos estudos negros. A terceira e última parte, intitulada Legitimação da fala: obstáculos para um autodidata, busca compreender a importância de Edison Carneiro no âmbito da pesquisa sobre o candomblé, da cultura popular e negra - a relevância que o mesmo desempenhou fora e dentro dos ambientes acadêmicos, tendo em vista a consolidação dos cursos de antropologia, sociologia e ciências sociais no Brasil, e a busca por cientificismo nos estudos culturais, como os feitos pela antropologia de Franz Boas e seus discípulos.

\footnotetext{
${ }^{2}$ Embora Rossi descreva que a pretensão do livro, fruto de sua tese, não seja fazer uma biografia do pesquisado, atribuo-a como uma rica fonte histórica para compreender a vida e os percalços que Edison Carneiro enfrentou em seu contexto social e político.
} 


\section{A história do ogã intelectual}

Ao falar de Edison Carneiro, sobretudo em sua trajetória, devemos antes, assim como fez Gustavo Rossi em seu livro, O Intelectual feiticeiro (ROSSI, 2015), destacar, resumidamente, o passado de seu ambiente familiar, para assim termos noção de como a história do autor se entrelaça ao ambiente intelectual baiano daquela época.

Em um ambiente familiar que participava ativamente do pensamento cultural e intelectual baiano, Edison Carneiro teve contato logo cedo com os grupos formados pelas oligarquias locais, principalmente pela presença do seu pai Antônio Joaquim de Souza Carneiro. Joaquim se formou em engenharia pela Faculdade Politécnica do Rio de Janeiro, e logo depois retornou à Bahia onde começou a dar aulas na Escola Politécnica de Salvador, se tornando catedrático posteriormente (BIAGGIO; COUCEIRO, 2009; ROSSI, 2015; GASPAR, 2017). Ficou conhecido como um intelectual polivalente, trabalhando e publicando seus textos nas mais variadas áreas: mineralogia, geologia, ensaios sociológicos, etnografia afro-brasileira e ameríndia, tornando-se reconhecido também como "bruxo" e "mago" devido a seus trabalhos místicos e esotéricos (ROSSI, 2015). Dito isso, é visível que o ambiente no qual o jovem Carneiro estava inserido, pela figura de seu pai, mantinha contatos com as elites oligarcas baianas, e sobretudo com a elite intelectual pensante da época. Pode-se dizer que Edison Carneiro seguiu o exemplo de seu pai, na sua polivalência e nos seus estudos que não se restringiam a uma única área, em que "as indefinições classificatórias que resvalaram na carreira intelectual de Edison Carneiro foram um sinal eloquente nesse sentido. Escritor, historiador, etnógrafo, jornalista, folclorista: ele foi todas elas, sem conseguir ser nenhuma delas por inteiro." (ROSSI, 2015, p. 31).

Edison Carneiro obteve destaque ao estudar os cultos afro-brasileiros e suas variantes, sobretudo a cultura negra e popular. Nos finais da década de 1920, ingressou na Academia dos Rebeldes, onde conviveria com outros intelectuais; formou-se em ciências jurídicas e sociais pela Faculdade de Direito da Bahia em 1935. Mas foi na Academia dos Rebeldes que teve sua adesão ideológica ao comunismo, tornando-se amigo de partido e estudos de Jorge Amado. Naquele momento, os jovens aspirantes a intelectuais da Bahia, envoltos na política local e nacional, observavam negativamente as 
mudanças da Revolução de Trinta e da política brasileira, principalmente na Bahia, encontrando formas para se opor ao governo, e foi no PCB que muitos desses jovens participaram ativamente da política baiana. Inclusive escrevendo na Revista Seiva, como descreve Gustavo Rossi (ROSSI, 2015, p. 157) “[...] que se tornou uma das principais, se não a única revista do partido, no contexto imediato à restauração do Estado Novo". Mas foi a partir de 1930, com os impasses trazidos pelo governo de Getúlio Vargas, que Carneiro começou a se debruçar sobre os estudos afro-brasileiros, principalmente na defesa dessas manifestações como particularidades ímpares para entender a cultura brasileira, como descreve Evelyn Marcele Mota:

\footnotetext{
Nesse período surge Edison Carneiro, entre os estudos sobre manifestações culturais adentrou o círculo da pesquisa, naquele momento a valorização da cultura brasileira pautava-se da ideia de preservação de tais manifestações, do samba de coco ao samba de roda, diversas instituições surgiram com a intenção de torná-las parte da identidade brasileira e, para isso, era necessário desvendar e preservar (MOTA, 2020, p. 38).
}

Carneiro obteve certo reconhecimento ao se debruçar sobre os "estudos negros", principalmente em sua carreira multifacetada. Atuou nas mais variadas áreas, assim como seu pai, transitando pela etnologia, etnografia, culturalismo, sociologia e antropologia, além de atuar como tradutor, redator, jornalista, professor e pesquisador. Teve passagens pelas mais variadas instituições e institutos, sendo contratado em 1936 para escrever no Jornal Estado da Bahia sobre as festividades do candomblé e seus cultos que eram realizados no estado, e em 1953, para redigir o boletim associado ao CNPq. Vista a importância que os baianos dão às festividades, e a evidência que tais terreiros estavam tendo, como o Gantois com a ialorixá mãe Menininha, como era mais conhecida; e o terreiro do Ilê Axé Opô Ofonjá governado por mãe Senhora (Maria Bibiana do Espírito Santo). Os trabalhos que Edison Carneiro desempenhou ao longo dos anos redigindo boletins para os jornais do estado da Bahia, foram importantes, pois a partir disso obteve o prestígio e respeito por parte dos praticantes do candomblé. Ele também foi um fator decisivo para inserção de intelectuais estrangeiros no candomblé, como será visto mais à frente.

Em 1937, junto com Arthur Ramos, atuou na organização do II ${ }^{\circ}$ Congresso AfroBrasileiro que ocorreu em Salvador, como destacou Gaspar, ao recuperar a fala que 
Carneiro fez na abertura do evento. E, ao final, organizou a criação da União das Seitas Afro-Brasileiras da Bahia (GASPAR, 2017).

[...] Este Congresso tem por fim estudar a influência do elemento africano no desenvolvimento do Brasil, sob o ponto de vista da etnografia, do folclore, da arte, da antropologia, da história, da sociologia, do direito, da psicologia social, enfim, de todos os problemas de relações de raça no país. Eminentemente científico, mas também eminentemente popular, o Congresso não reúne apenas trabalhos de especialistas e intelectuais do Brasil e do estrangeiro, mas também interessa a massa popular, aos elementos ligados, por tradições de cultura, por atavismo ou por quaisquer outras razões, à própria vida artística, econômica, religiosa, do Negro do Brasil. [...] (CARNEIRO, 1937 apud GASPAR, 2017).

Edison Carneiro teve contato com inúmeros intelectuais que, a partir da década 1930, se debruçaram sobre assuntos da população negra, entre eles Arthur Ramos e Gilberto Freyre. Podemos dizer que a referência dos dois para Carneiro foi importante como chave de compreensão do que estava sendo escrito e falado sobre o assunto. Como destaca Gustavo Rossi, eles eram os "donos do assunto", o que causou atritos entre os autores sobre a especificidade da escrita de Carneiro, numa linguagem acessível e rebelde, fora dos padrões que os intelectuais acadêmicos exigiam no processo de institucionalização dos cursos de sociologia e antropologia. Durante toda a década de 1930, inúmeros estudos sobre o candomblé e a população negra vinham sendo desenvolvidos. Nesse período, alguns obtiveram destaque como, - além dos mencionados Gilberto Freyre e Arthur Ramos - Oracy Nogueira, Roger Bastide, Luiz de Aguiar Costa Pinto, René Ribeiro, Donald Pierson e os estudos da escola de Sociologia de Chicago, entre outros intelectuais que marcaram o pensamento sociológico e brasileiro naquele contexto, buscando entender as especificidades do que ficou conhecido como democracia racial.

Nina Rodrigues, intelectual oriundo do Maranhão, professor e influente antropólogo e médico, também desempenhou uma importante influência em Carneiro, sobretudo na sua forma de pesquisar o negro brasileiro, colocando os estudos sobre a população negra como uma questão social. Apesar de que, assim como outros intelectuais do século XIX, vai adotar como base a ciência eurocêntrica que chegava aos trópicos, adotando as ideias de Cesare Lombroso, e chegando a conclusões de degeneração e inferioridade da raça, e miscigenação como algo negativo (SCHWARCZ, 1993). Os trabalhos de Rodrigues foram amplamente divulgados no país, sobretudo na Escola de 
Medicina da Bahia, onde lecionava e fez boa parte de suas pesquisas. Mesmo após a morte do médico, suas ideias e conclusões ainda pairavam no ar dos "homens de sciencia", como aponta Lilia Schwarcz (SCHWARCZ, 1993). Sendo considerado o primeiro a colocar o negro como objeto de estudo científico no país, e como questão social (SCHWARCZ, 1993; ROSSI, 2015).

Edison Carneiro teve em Nina Rodrigues um espelho de como estudar o negro, embora as perspectivas de ambos os autores divergissem, principalmente no tocante às religiões de matrizes africanas. Enquanto Nina Rodrigues via nas manifestações afrobrasileiras um modelo de comparação utilizando um referencial católico (SERAFIM, 2013), no qual “'...] as atitudes e os comportamentos dos negros, ainda que socialmente reprováveis ou 'bárbaros' do ponto de vista das raças consideradas superiores, como era o caso dos candomblés, não deveriam ser repreendidos pela opinião pública e pelos órgãos do Estado [...]" (ROSSI, 2015, p. 172). Carneiro, entretanto, vai pautar uma defesa do candomblé e das culturas afro-brasileiras, principalmente a popular, e trazer o objeto de estudo para dentro de seus trabalhos como participantes ativos; como descreve Gustavo Rossi, ele "[...] realizou uma apropriação criativa e original de Nina Rodrigues, forjando abordagens que não constituíram meros desdobramentos daquelas produzidas por Arthur Ramos no tocante à cultura afro-brasileira" (ROSSI, 2015, p. 170).

Com sua ida ao Rio de Janeiro em 1939, e sua linhagem de estudos já consolidada, Edison Carneiro trabalhou em inúmeras funções, tanto como pesquisador quanto docente na Biblioteca Nacional, ministrando aulas no curso de biblioteconomia sobre bibliografia do folclore. Em seguida, passou a ser professor visitante de outras instituições, como a Universidade Federal de Minas Gerais, Universidade Federal da Bahia, Universidade Federal de Pernambuco e Universidade Federal do Rio Grande do Sul (ROSSI, 2015; GASPAR, 2017). Ainda no Rio de Janeiro, Carneiro passou a ser colaborador do $O$ Jornal; posteriormente, patrocinado pelo Museu Nacional, foi enviado à Bahia para coletar material sobre cultos populares e encomendar bonecas de pano em tamanho natural, vestidas como as diversas divindades africanas. Teve, em 1969, o agraciamento do prêmio Machado de Assis pela Academia Brasileira de Letras, sendo premiado também com as medalhas Sílvio Romero e Euclides da Cunha. 
Em sua trajetória, marcada por conflitos pessoais e sociais, Carneiro conheceu Ruth Landes, antropóloga e etnóloga americana, que veio ao Brasil em 1938 para realizar pesquisas sobre as relações raciais. Assim como Landes, Carneiro deu abertura a inúmeros intelectuais que vinham de fora para estudar o candomblé na Bahia, como o antropólogo Charles Wagley e o fotógrafo e antropólogo Pierre Verger.

Ao falar sobre Edison Carneiro, sobretudo de sua trajetória, é necessário e pertinente reafirmar a sua condição de negro, mesmo não sendo de pele retinta, mas a família dos Souza Carneiro, que dispunha da mesma condição racial, sofreu por um "embranquecimento" dentro da sociedade baiana, e para se reafirmar como intelectual, tanto seu pai quanto Carneiro eram vistos como "mulatos" ou "quase brancos", o que pode explicar sua "facilidade" de inserção dentro do campo intelectual, predominantemente branco. Mantinha uma relação de prestígio e respeito com o povo do candomblé, principalmente as matriarcas e pais de santos e com os praticantes, sendo o primeiro a defender publicamente o candomblé, e tendo inúmeros trabalhos nos jornais da Bahia sobre as religiões de matrizes africanas.

Edison Carneiro morreu em 1972, no dia 2 de dezembro, deixando um legado riquíssimo de contato com os terreiros de candomblé, que passaram por um processo de legalização e de institucionalização como parte fundamental da cultura brasileira durante as décadas de 1930 e 1940 . Neste sentido, o pensador baiano, durante toda sua trajetória como intelectual, sempre deixou clara sua posição de defensor da religião e da cultura popular, assim como participou ferrenhamente da campanha em defesa do folclore nacional como membro do conselho técnico do MEC (GASPAR, 2017). Aydano do Couto Ferraz, seu amigo íntimo, demonstrou que ele, ao final da sua vida, estava deprimido, pois sentia-se como um intelectual frustrado e abandonado pela academia que poderia ter feito mais aos estudos da cultura afro-brasileira e para a sociedade, essa era a concepção de Carneiro diante da sua trajetória.

Sua imensa obra demonstra o papel que desempenhou com afinco para entender e analisar a cultura que ainda há de ser desbravada pelas próximas gerações. Não só por seus textos e ensinamentos, mas por seu legado como ogã, cargo de prestígio dado aos participantes do candomblé, e, sobretudo, por seu intelectualismo que não se dissociou da figura de pensador e admirador das religiões de matrizes africanas, e, principalmente da 
cultura popular. Como ele mesmo mostra em seu livro A sabedoria popular que "há muito de inocente, e mesmo acomodatício, nas coisas do folclore, mas há também muito de reivindicação social, pois, atualizando-se constantemente, em resposta aos incitamentos da hora, o folclore se projeta no futuro" (CARNEIRO, 2008b, p. 08).

\section{Da "quase" branquitude aos estudos negros}

Ao referenciar a obra do autor, foi possível traçar um projeto de análise que ele desempenhou, indo do candomblé baiano à cultura popular, da sociologia à antropologia. Edison Carneiro teve mais de uma dezena de livros publicados, mas foi a partir de 1933, com alguns trabalhos que teve proeminência dentro do campo de estudos sobre as religiões de matrizes africanas e cultura popular.

Entre suas obras, podemos destacar Religiões negras: notas de etnografia religiosa, publicada em 1936; Negros bantus, publicada em 1937; Candomblés da Bahia, publicada em 1948; A sabedoria popular, publicada em 1957; Ladinos e crioulos: estudo sobre o negro no Brasil, publicado em 1964; Dinâmica do folclore, publicado em 1965 e Capoeira, publicado postumamente em 1975.

Ao apresentar suas obras, podemos ver que o tema da negritude e do candomblé nunca saíram do seu repertório, nem das suas pesquisas, permaneceram até mesmo nos poemas, feitos em sua adolescência, muitos deles sendo publicados pelos jornais da Bahia. Mesmo na docência, Carneiro desempenhava sua função de estudioso/pesquisador da cultura popular e da cultura negra, sendo refletida nas suas disciplinas e eventos dos quais participava e organizava. A exemplo do primeiro Congresso do Negro Brasileiro, do qual participou em 1950, momento em que as teses sobre a população negra estavam no auge das pesquisas, devido ao Projeto $\operatorname{Unesco}^{3}$ e às concepções de democracia racial empregadas e difundidas nacional e internacionalmente. Carneiro, nesse evento,

\footnotetext{
${ }^{3} \mathrm{O}$ projeto Unesco tinha como pressuposto localizar e demonstrar como as raças viviam em harmonia no país, principalmente no pós-guerra. Com a contribuição de Gilberto Freyre em Casa-Grande e senzala, a ideia de harmonia entre raças foi difundida e divulgada mundialmente, transformando o Brasil numa espécie de laboratório de experiências. Entretanto foi constatado com inúmeros estudos que o país vivia sob a distinção racial e de classe. Não havendo harmonia, sendo demonstrado nos principais estudos da expedição no país do que se convencionou chamar de Escola Paulista de Sociologia.
} 
apresentou duas teses, uma sobre $O$ quilombo de Carlota cujo relator foi Roger Bastide, e a tese Iemanjá e a mãe-d'água tendo como relator Sebastião Rodrigues Alves. Além disso, ele foi relator de inúmeros trabalhos apresentados ao longo dos seis dias de evento (PEREIRA; SANSONE, 2007). Em 1955, elaborou junto com Luiz Aguiar Costa Pinto um relatório para Coordenação de Aperfeiçoamento do Pessoal de Nível Superior Capes, mostrando os rumos da sociologia no Brasil, seus impasses e problemas no momento de institucionalização de grupos de pesquisa, institutos e centros acadêmicos voltados à pesquisa sociológica.

Como podemos observar ao longo deste trabalho, a trajetória do autor, além de singular, demonstra que seu fascínio pelo candomblé se sucedeu num dos seus mais belos trabalhos, Candomblés da Bahia, sobre o qual nos deteremos um pouco mais devido à importância teórica e metodológica que ela ainda desempenha nos estudos sobre cultura afro-brasileira e religiões de matrizes africanas.

Ao ter contato com a obra de Edison Carneiro, podemos acentuar que as religiões afro-brasileiras desempenham uma função social, cultural e moral que nos ajuda a compreender a cultura brasileira, o misticismo, o ocultismo que a religião tem, e a cultura secular que ela desempenha além muros da África no Brasil. Candomblés da Bahia teve sua primeira publicação em 1948, obteve diversas reedições até a mais recente da editora Martins Fontes, de 2008.

Para entender a obra, o autor faz um trajeto de interlocução com o leitor para o levar ao mundo do candomblé, buscando desvendar suas nações, cultura(s), orixás cultuados, cânticos, dialetos, objetos sagrados e o modelo econômico vigente em cada terreiro, situando assim seu modelo hierárquico. A edição de 2008 não difere muito da primeira publicação de 1948, contendo nove capítulos, mais a introdução. Separando-os por partes, o primeiro capítulo diz respeito ao conhecimento da casa de candomblé, sua fisionomia e modelo, trazendo desenhos das divisões da casa, estrutura dos quartos para os iniciados, e dos quartos para determinados cultos e orixás.

O segundo capítulo dá importância à relação entre os "modelos atuais" e os que sofreram processos de sincretismo com santos oriundos da religião católica. No capítulo três, destaca a importância das festividades no terreiro e sua dimensão simbólica e social dentro da comunidade. Carneiro traz também em sua análise os incidentes que podem 
ocorrer durante a festa, os preparos e pós festa, os eventos que acontecem quando só os filhos de santos ficam no terreiro, o que a deixa a descrição mais rica de detalhes. O quarto capítulo vai explicar a relação entre os orixás e suas características para cada nação, suas comidas preferidas e suas datas comemorativas. No quinto capítulo, a liturgia ganha centralidade, os atabaques, sua dimensão basilar dentro dos terreiros e a relação entre a natureza e o candomblé é percebida e analisada por Edison Carneiro ao contemplar a importância dos banhos de ervas e rituais de purificação que acontecem dentro dos terreiros.

No sexto capítulo, a questão passa a ser pautada pela relação entre o filho de santo que está passando pela feitura e seu orixá, o momento único da iniciação e aprendizado dos cânticos, comidas e roupas. As relações socioafetivas que as mães e pais de santo desempenham dentro da comunidade; nesse momento, Edison Carneiro traz para seu trabalho as relações que são desempenhadas por grandes ialorixás, como mãe Aninha, Maria Neném e Flaviana.

No capítulo sete, volta a analisar a questão das mães (ialorixás) e pais de santo (babalorixás). A presença cada vez mais presente dos homens como governantes das casas de candomblé, e a percepção matriarcal que o candomblé tem na sua relação com as mulheres e seus postos de comando, influencia que pode ser vista no livro de Ruth Landes (LANDES, 1967). Nos dois últimos capítulo, oito e nove, Carneiro busca analisar a divisão dos poderes espirituais do terreiro, as funções que cada filho de santo desempenha na casa, sendo elas bem específicas para cada um, a importância do culto e a relação que os filhos de santos têm com o "axé", como o "terreiro" é conhecido entre os candomblecistas. Até mesmo a socialização, que certas mães de santo têm com seus mais de cem filhos de santo, é destacada no estudo de Edison Carneiro. E por último, fala sobre o gradual desparecimento dos babalaôs, os sacerdotes de Ifá, responsáveis pelo jogo divinatório do candomblé.

A descrição do livro, feita acima, nos ajuda a argumentar sobre as contribuições que o autor lança sobre os estudos culturais e raciais em seus trabalhos. Primeiro, por seu olhar sob o negro pelo prisma do comunismo, adotando-a como uma forma de analisar e estudar as religiões de matrizes africanas e das culturas afro-brasileiras (ROSSI, 2015; SCHWARCZ, 2008); segundo, pela forma como em seus estudos, sua militância não se 
dissociou da figura de intelectual, possibilitando atuar politicamente no campo dos estudos raciais e culturais. Lilia Schwarcz revela a perseverança de Carneiro ao destacar em seus estudos a singularidade da cultura popular do negro, a autenticidade de suas manifestações, como distintivo de uma cultura desconhecida ou até então menosprezada (SCHWARCZ, 2008).

Assim como possibilitou a inserção de novas formas de se fazer pesquisa de campo, seja pelo seu olhar antropológico ao caráter cultural, religioso e material das casas de candomblé; e sociológico por sua percepção da dimensão social que os terreiros desempenham até hoje, para além das marcações geográficas do local. Biaggio Talento e Luiz Alberto Couceiro destacam como as influências dos estudo etnográficos de Carneiro foram exploradas por autores como Roberto DaMatta, Luiz Fernando Dias Duarte, Edlaine de Campos Gomes (BIAGGIO; COUCEIRO, 2009, p. 183). Em um momento no qual os trabalhos etnográficos estavam em alta nas décadas de 1930 e 1950, o surgimento de etnografias com rigor de detalhes, fez da obra de Carneiro um importante "manual" de trabalho de campo e de pesquisa, que "o leitor permanentemente tem a ideia de que não só Edison esteve e está nos terreiros de candomblé de Salvador, como conhece com alguma intimidade seu cotidiano e o das pessoas que os sustentam religiosa e materialmente" (BIAGGIO; COUCEIRO, 2009, p. 183). Os autores destacam a importância que sua etnografia desempenhou na antropologia da época.

[...] de modo semelhante à Malinowski, especificamente ao 'Capítulo XVIII: A magia do Kula' d'Os Argonautas do Pacífico Ocidental, procurou em seus trabalhos sobre religiões de origem africana no Brasil responder a três questões básicas: 1) o que a magia significa para os nativos? 2) Quais são os seus elementos nativos? 3) Quais são os elementos objetivos e explicativos dos nativos para o ato mágico? (BIAGGIO; COUCEIRO, 2009, p. 184).

Sua compreensão do funcionamento do candomblé, dos rituais, das festas e do misticismo, contribuiu para desmistificar o preconceito existente sobre as religiões de matrizes africanas. Sobretudo a cultura popular e periférica da população negra, na sua defesa de que o candomblé seria um pilar da cultura brasileira, devido a sua história, pelo povo que perpetua com afinco os ensinamentos de seus antepassados com respeito e orgulho de forma oral e autônoma. Metodologicamente, Carneiro não fez escola, ou deixou "discípulos", mesmo ele tendo inovado no campo de estudos sobre cultura, sobre 
as diversas formas com que fazia seus trabalhos de campo e lidava com os dados de sua pesquisa. Sendo demonstrado em seus trabalhos a solidez que seus estudos desempenharam no meio intelectual já consolidado no campo institucional das ciências sociais.

Embora as críticas a Carneiro pairassem sobre sua militância, sua escrita rebelde ou pelo teor ensaístico de seus estudos, no momento de formação do "ethos" acadêmico das ciências sociais no Brasil, intelectuais como Carneiro multifacetados, foram profundamente afetados por suas atuações que não se enquadravam no processo de institucionalização dos cursos de ciências sociais, vindo a combater justamente o tipo de intelectual que ele fazia jus a ser: autodidata e polígrafo. Carneiro representava não só um intelectual com notório saber, mas um exímio pesquisador dos temas antropológicos e sociológicos sobre os estudos da população negra e da religião, porém, no meio institucional, sem o diploma ficava a mercê da subalternidade diante dos intelectuais diplomados em antropologia ou sociologia.

\section{Legitimação da fala: obstáculos para um autodidata ${ }^{4}$}

Para uma melhor compreensão do argumento destinado a esta parte do artigo, revisitaremos, de forma breve, as particularidades e disputas do campo acadêmico perpassando o que Lilia Schwarcz, em seu livro Espetáculo das raças (SCHWARCZ, 1993), chama de cultura do "bacharel" e que, com a institucionalização dos cursos de sociologia e ciências sociais no país, vai resvalar em figuras como a de Edison Carneiro, buscando um padrão de quem realmente poderia falar como cientista social, relegando aqueles que não se encaixam nos padrões à subalternidade.

No momento de consolidação dos cursos superiores no Brasil, as elites oligárquicas que antes se viam obrigadas a mandar seus filhos para fora do país, agora ressurgem enviando aos estados onde os cursos foram sediados, principalmente: Recife, Bahia e Rio de Janeiro, para cursar direito e medicina. Durante todo século XIX e início

\footnotetext{
${ }^{4}$ Cabe aqui descrever que o termo "autodidata" comumente utilizado, revela-se para fins de argumentação, não no sentido estrito do termo, mas como o utilizou Gustavo Rossi (ROSSI, 2015): expressar o entendimento das disputas de campo presentes, e das exclusões que atingiram intelectuais que tentavam se inserir de forma institucional na área como Edison Carneiro.
} 
do $\mathrm{XX}$, os bacharéis obtiveram status político e social, não só pelas atribuições políticas que estavam abertas a ocupar, mas, sobretudo, para arranjos familiares com casamentos arrumados a fim de manter o prestígio e distinção entre as classes sociais e políticas (SCHWARCZ, 1993). Na primeira geração de docentes que foram convidados a dar aulas nas recém criadas faculdades de direito no país, a maioria era estrangeira, especialmente, franceses e americanos. Com a formação dos intelectuais brasileiros que estudavam no exterior e nas faculdades brasileiras, surge a importância de se estudar o país, a partir da ótica nacional de seus próprios cidadãos.

No processo político e social em que se encontrava o país após a Revolução de Trinta, surge o processo de institucionalização das ciências sociais, principalmente com a criação da Faculdade de Filosofia, Ciências e Letras na Universidade de São Paulo em 1934 e a Escola Livre de Sociologia e Política, também em São Paulo em 1933. Com o processo de legitimar a ciência social no Brasil, resvala nos bacharéis, que antes falavam como detentores do "conhecimento social”, e emergem “os estágios de 'transição' das ciências sociais em que começaram a se desenvolver os rituais de instituição" (ROSSI, 2015), acarretando uma disputa de campo de quem poderia falar como sociólogo e quem era formado na área para se intitular como tal. Gilberto Freyre, em seu livro Sobrados e mucambos (FREYRE, 2015), traça uma linha de argumentação que mostra como o processo de transição do mundo rural ao urbano vai declinando o status do bacharel em direito, principalmente no processo de cisão entre o patriarcal e o moderno, e com o surgimento de novas áreas de conhecimento.

As disputas dentro do campo intelectual e institucional marcam as ciências sociais e humanas, principalmente no Brasil, seja nos métodos, abordagens, fatores e objetos estudados. Nesse momento, dentro do campo institucional, figuras como a de Edison Carneiro vão revelar o "processo pelo inverso, uma vez que ele passou a personificar o modelo de intelectual que as ciências sociais modernas buscaram justamente combater e expelir como cientificamente autorizados a falar sobre o social" (ROSSI, 2015, p. 31). Dentro do campo das relações raciais, religiosa e da cultura, exerceu trabalho e pesquisas riquíssimas em dados que até hoje são portfólio para pesquisadores, seguindo uma linha que ainda é utilizada como bibliografia, e tido como indispensável para se estudar antropologia no Brasil, principalmente na linha cultural e folclórica. 
Embora Carneiro tivesse formação em ciências jurídicas e sociais, isso o impossibilitou de adentrar no campo institucional de forma estrita do termo, mesmo tendo contato e conhecimento da antropologia e sociologia da época, o pensador não desfrutou dos passes que a academia dava aos demais. Primeiro, porque existia naquele momento de institucionalização, uma delimitação de quem tinha o direito de falar como antropólogo e sociólogo (MAZUCATO, 2014; MICELLI, 1989). Amurabi Oliveira reforça como essas disputas atingem intelectuais que são colocados na subalternidade ou excluídos:

No caso brasileiro também se percebem as assimetrias das relações de poder
existentes, enquanto Ramos ocupou um papel de destaque na
institucionalização da antropologia brasileira [...] Carneiro, por exemplo,
nunca conseguiu ter uma inserção acadêmica no sentido estrito no Brasil.
Quando Ramos faleceu em 1949 e foi aberta uma vaga na Universidade do
Brasil, Carneiro tentou se inscrever para o concurso, porém sua inscrição foi
indeferida, assim como de Heloisa Alberto Torres (OLIVEIRA, 2017, p. 609).

E conclui dizendo que as inscrições não foram homologadas pela ausência de diplomas universitários, mesmo sendo requerido por ambos o reconhecimento de notório saber (OLIVEIRA, 2017).

No campo da sociologia e antropologia da religião, os estudos de Edison Carneiro são utilizados, sobretudo pela sua percepção das relações e nuances que estão direta e indiretamente circunscritas no ambiente do candomblé, como exemplos práticos de pesquisa de campo e etnografia. Seus trabalhos ricos em detalhes, demonstram como seu autodidatismo não o impediu de fazer trabalhos magníficos, com aportes históricos e sociais dos candomblés do país. Por outro lado, no campo do pensamento social brasileiro, área em que a obra de Edison Carneiro ainda não é amplamente utilizada, seus trabalhos permanecem desconhecidos por muitos. Atualmente, há cada vez mais a busca por intelectuais negros que sofreram exclusões frente à hegemonia dos intelectuais brancos. Embora os trabalhos dele não sejam utilizados para compreender a questão nacional, como fizeram Darcy Ribeiro, Caio Prado Junior, Sérgio Buarque de Holanda etc., eles são importantes documentos que ajudam a recriar o ambiente da população negra e periférica nas décadas pós Revolução de Trinta e Estado Novo, como descrevem Paulina Alberto e Antonio Sérgio Guimarães: como a democracia racial sobrepôs aos intelectuais 
negros lugares marginalizados dentro das instituições, universidades e dos intérpretes já consolidados (GUIMARÃES, 1999; ALBERTO, 2017).

Em meio a todas essas disputas do campo, Carneiro desempenhou sua função com afinco até sua morte, mesmo relegado a vender seus trabalhos a jornais e revistas, e sendo pouco reconhecido como um pesquisador (MOTA, 2020). Deixou um legado de contribuições para os campos das ciências sociais, sobretudo nos estudos de raça, cultura popular e religião.

\section{Considerações finais}

Ao concluir este texto sobre Edison Carneiro, deve-se levar em consideração que o autor nos ajuda a compreender os impasses das populações negras e das religiões de matrizes africanas em seu tempo e contexto, principalmente no quesito cultura, tema defendido incessantemente por ele.

É importante dizer que Carneiro, nesse período, como um pesquisador autodidata não era reconhecido homogeneamente por todos como um antropólogo ou sociólogo. Dito isso, o caminho que delineamos neste texto teve como particularidade demonstrar ao leitor a importância do autor dentro do campo de estudos raciais e religiosos, chamando a atenção para o fato de ainda ser um intelectual pouco estudado no campo do pensamento social. É necessário que seja desbravado e (re)conhecido por seus trabalhos que nos ajudam a compreender a cultura e os indivíduos, mesmo quarenta e sete anos após sua morte. Seus estudos são elencados até hoje por muitos pesquisadores, dentro e fora das ciências sociais, tanto para compreensão dos arranjos sociais das religiões de matrizes africanas quanto para entender as noções de cultura popular no Brasil.

A sua trajetória pode ser comparada com a de outros intelectuais conhecidos pelos estudantes de ciências sociais, não vindo de família aristocrática como Caio Prado Júnior, ou pobre como Florestan Fernandes. Carneiro, diferentemente, transitava entre a míngua e a fartura. Socialmente, pôde frequentar grupos intelectuais da Bahia, fazendo com que seu acesso a esses grupos fosse mais fácil, talvez pela presença do seu pai. As amizades que construiu nesse período, e que levou para a vida, são hoje reconhecidas nacional e 
internacionalmente, entre elas, podemos destacar Jorge Amado, amigo íntimo e de lutas políticas.

E por fim, é importante destacar a importância de Edison Carneiro para os estudos antropológicos brasileiros, mesmo obtendo certo reconhecimento tardio, fez com maestria as suas pesquisas dentro do campo do folclore, que na época era visto como "tema ultrapassado" e concluiu, assim como Sílvio Romero, que a necessidade de estudar a cultura negra e o folclore é importante para estabelecer conexões entre o passado e o futuro, em que "o conjunto do folclore, tanto de ordem espiritual como de ordem material, contém, dado o seu caráter eminentemente popular, ecumênico, a essência nacional" (CARNEIRO, 2008b, p. 9).

Por isso, dentro do contexto atual em que vivemos, conhecer a cultura e seus intelectuais que auxiliaram a estabelecer conexões entre passado e futuro é de suma importância para analisar a nossa sociedade. Finalmente, Edison Carneiro, além de autodidata e polígrafo, é referência para estudar as religiões de matrizes africanas, por uma lente decolonial e marxista, pondo em xeque o establishment de autores hegemônicos dentro da academia, majoritariamente brancos. Ele contribui para compreensão das particularidades que estavam em disputa na formação do campo de estudos "negros" no país, e seus trabalhos podem ser utilizados para analisar e descrever processos de desenvolvimento da cultura e religião a partir da nossa realidade e da importância que os meios culturais têm para a vida social.

\section{Referências}

ALBERTO, Paulina. Termos de inclusão: intelectuais negros brasileiros no século XX. Campinas, SP: Editora da Unicamp, 2017.

AMADO, Jorge. Bahia de todos os santos: guia das ruas e dos mistérios da cidade do Salvador. São Paulo, Martins, 1973.

BIAGGIO, Talento.; COUCEIRO, Luiz Alberto. Édison Carneiro, o mestre antigo: um estudo sobre a trajetória de um intelectual. Salvador: Assembleia Legislativa do Estado da Bahia, 2009. 
CARNEIRO, Edison. Candomblés da Bahia. 9. ed. São Paulo: Editora WMF Martins Fontes, 2008a. [1948].

CARNEIRO, Edison. A sabedoria popular. 3. ed. São Paulo: Editora WMF Martins Fontes, 2008b. [1957].

FREYRE, Gilberto. Sobrados e mucambos. São Paulo: Global Editora e Distribuidora Ltda, 2015. [1936].

GASPAR, Lúcia. Edison Carneiro. Recife: Fundação Joaquim Nabuco, 2017. Disponível em: http://basilio.fundaj.gov.br/pesquisaescolar/index.php?option=com content\&view $=$ article $\&$ id $=759 \% 3$ Aedison-carneiro\&catid $=40 \% 3$ Aletra-e $\&$ Itemid $=1$. Acesso em: 10 de set. 2020.

GUIMARÃES, Antonio Sérgio Alfredo. Raça e os estudos de relações raciais no Brasil. Novos Estudos CEBRAP, São Paulo, v. 54, p. 147-156, 1999. Disponível em: https://www.pragmatismopolitico.com.br/wp-content/uploads/2018/11/GUIMARAES$\mathrm{Ra} \% \mathrm{C} 3 \% \mathrm{~A} 7 \mathrm{a}-\mathrm{e}-\mathrm{os}-\mathrm{estudos}-\mathrm{de}-\mathrm{rela} \% \mathrm{C} 3 \% \mathrm{~A} 7 \% \mathrm{C} 3 \% \mathrm{~B} 5$ es-raciais-no-Brasil.pdf. Acesso em: 10 de set. 2020.

LANDES, Ruth. A cidade das mulheres. Rio de Janeiro: Civilização Brasileira, 1967.

MAZUCATO, Thiago Pereira da Silva. Florestan Fernandes e a consolidação das ciências sociais no Brasil: da Antropologia e Sociologia à Ciência Política. Revista Florestan, São Carlos, p. 3-11, 2014. Disponível em: http://www.revistaflorestan.ufscar. br/index.php/Florestan/article/viewFile/9/pdf_6. Acesso em: 10 de set. 2020.

MICELI, Sergio et al. História das ciências sociais no Brasil. São Paulo: IDESP, 1989.

MOTA, Evelyn Marcele Ribeiro. Edison Carneiro, o negro da cor trigueira: inserção, audácia e invisibilidade. COSMOS-Revista de Graduação em Ciências Sociais, Aracaju, v. 1, n. 1. p. 37-57, 2020. Disponível em: https://seer.ufs.br/index.php /COSMOS/article/view/13867. Acesso em: 10 de set. 2020.

OLIVEIRA, Amurabi. Amizades e inimizades na formação dos estudos afro-brasileiros. Latitude, Maceió, v. 12, n. 2, p. 589-617, 2017. Disponível em: https://www.seer.ufal.br/index.php/latitude/article/view/4031/pdf. Acesso em: 10 de set. 2020 .

PEREIRA, Cláudio Luiz; SANSONE, Livio. Projeto UNESCO no Brasil: textos críticos. Salvador: Edufba, 2007.

ROSSI, Luiz Gustavo Freitas. O intelectual "feiticeiro": Edison Carneiro e o campo de estudos das relações raciais no Brasil. Campinas, SP: Editora da Unicamp, 2015.

SERAFIM, Vanda Fortuna. Nina Rodrigues e as religiões afro-brasileiras: a" formalidade das práticas" católicas no estudo comparado das religiões (Bahia-século XIX). 2013. 333 p. Tese (Doutorado em História) - Centro de Filosofia e Ciências 
Humanas, Universidade Federal de Santa Catarina, Florianópolis, 2013. Disponível em: https://repositorio.ufsc.br/handle/123456789/107536. Acesso em: 09 de set. 2020.

SOARES, Angelo Barroso Costa. Academia dos rebeldes: modernismo à moda baiana. 2006. 204 p. Dissertação (Mestrado em Literatura e Cultura) - Universidade Estadual de Feira de Santana, Feira de Santana, 2006. Disponível em: http://www.dominiopublico.gov.br/pesquisa/DetalheObraForm.do?select_action=\&co obra=22792. Acesso em: 9 de set. 2020.

SCHWARCZ, Lilia Moritz. O espetáculo das raças: cientistas, instituições e questão racial no Brasil do século XIX. São Paulo: Companhia das Letras, 1993.

SCHWARCZ, Lilia Moritz. (Resenha do livro A sabedoria popular de Edson Carneiro). Revista de Antropologia, São Paulo, v. 51, n. 1, p. 327-332, 2008. DOI: https://doi.org/10.1590/S0034-77012008000100015. Disponível em: http://www.revis tas.usp.br/ra/article/view/27313. Acesso em: 9 set. 2020.

Recebido em: 24/08/20.

Aceito em: 07/10/20. 